Chapter 9

\title{
Combustion of Municipal Solid Waste for Power Production
}

\author{
Filip Kokalj and Niko Samec \\ Additional information is available at the end of the chapter
}

http://dx.doi.org/10.5772/55497

\section{Introduction}

Modern societies create more and more waste per capita and we, even personally, are all a part of this process. For most of the people the "management" and the "problem" of waste ends when municipal solid waste (MSW) is placed in a container.

In waste management we must adhere to a hierarchy that puts focus on reducing the quantities, then re-use and recycling. Only then the energy utilization comes, followed by disposal.[9]

The average MSW in developed countries has a calorific value between 8 and $12 \mathrm{MJ} / \mathrm{kg}$. Based on this property the MSW can be compared with the fresh wood or lignite, which is low grade coal. The amount of waste generated is still slightly rising over the years with some fluctuations, due to general economy reasons (at the time of writing - recession) and technical measures in waste management in recent years. The amount of deposited MSW at landfills is getting lower in recent year despite the rise of total generated MSW due to better separate collection and treatment technologies utilized.

Developing countries in general produce more wet waste with lower calorific value but if dried it can easily reach above calorific values. The improvement of waste collection and treatment in those countries is slow and mostly not integrated.

Data on waste quantity, composition and treatment streams can be found at local statistical offices data bases or on global level from regional (like European Union) or international organizations (United Nations or World Bank). Very good data on waste that is updated and comparable between continents and nations can be found for instance in World Bank publications [6]. This data shows the average global waste generation per capita by regions from 0.45 to $2.2 \mathrm{~kg} / \mathrm{capita} /$ day. Similar data can also be found in United Nations data base [16]. 
The majority of waste worldwide is currently still being disposed of on landfills without any or proper treatment. The landfills itself are mostly just big deposit sites located in valleys or depressions without any protection of ground water. This means that fast total quantity of waste ends on landfills.

Some developing countries have in recent years successfully introduced material recovery of separately collected fractions and mechanical and biological treatment (MBT) of waste. The latter has somewhat reduced emissions of greenhouse gases from waste disposal.

Developed countries have based the waste management on the separate collection of various waste fractions. In most developed countries is in power for over 40 year. The separate collection waste process is long improving process and needs continuous education of all generations, especially youth at school of all grades, from kindergarten to high school. The payment system of waste collection also motivates population to separately collect and discharge fraction in appropriate bins.

Local, regional and national integrated waste management concept is composed of many closely related and connected technical and technological processes. With the aim to establish an environmentally and economically acceptable waste management it is essential for all the technological and logistical steps in the process of waste management to be interlinked and harmonized.

The MBT technologies are being introduces in regional waste treatment centers for the treatment of residual waste. This minimizes the mass and stabilizes waste before mostly being put directly to landfill. On the other hand this treatment can prepare relatively constant quality waste fraction with good calorific value ready to utilize in standard or advanced waste - to energy (W-t-E) plants.

The energy utilization of waste is justified in energy and environmental sense and it is obligatory to fulfill local legislation and in case of Europe also European waste directive demands. [5], [9]. In doing so there must be meeting all legal requirements that define the process of waste incineration or rather called waste to energy (W-t-E) process. [5] Heat generated can be used to produce power (electricity), hot water for heating and cool media for cooling.

Theyearly amount of energy contained in wastegenerated by an average European Union family is such that they would be able hypothetically to entirely heat up low energy house of reasonable size all season. Incineration of waste in a centralized system of larger capacity is environmentally, technically and economically feasible, thus a solution for W-t-E at regional level.

The utilization of energy in waste can be technically achieved with many different technologies. As W-t-E plants are rather moderate to big size facilities they produce power and hot water or steam with the energy of waste. Deferent technologies enable distinct approaches for utilization of enthalpy in different thermal machines that are capable to transform this enthalpy into mechanical and then into power.

All these processes need to follow strict environmental standards to avoid any negative impacts into the air, water or soil. Thus, the process must be regarded as a whole, not letting any material of energy flow out without environmental considerations. 


\section{Municipal solid waste characteristics}

Waste treatment technology, where applied, is nowadays a highly developed and advanced activity with constant and extensive public control. Specially developed combustors for waste incineration are inevitably needed in every modern and civilized society.

Nowadays, bed combustion on grate is the most common way to incinerate municipal solid waste and generate electrical power and heat. [2] The combustion in these plants is very specific due to the characteristics of municipal solid waste which depends on collection, pretreatment, season of the year, etc. [13] The goal of every technology producer on one side and the operators on the other side is the optimal thermal conversion of calorific energy of waste into electrical power and heat with minimal emission of the pollutants to the environment.

A considerable decrease in amounts of municipal waste from commerce is expected due to the regulation on waste packaging material in developed countries and the aim to lower the costs in commerce in general. At the same time an increase in the quantity if household waste is expected. The fact is that an increase in the gross domestic product and peoples' living standard is consequentially shown also as increase in waste quantities.

Structure of the waste and its components are very much a factor of nation development and wealth. In Table 1 is presented the average structure of the municipal solid waste and comparison to other developed countries show that the structure is very similar. In developing countries the average structure has less packaging material (paper, plastic) thus has in fresh state lower calorific value as waste from developed countries.

Structure of the waste (Table 1) varies depending on season and weather conditions. It also depends on the contribution region (rural, urban,...), which influences the moisture and biodegradable waste share.

The average waste material utilized in $\mathrm{W}$-t-E process is composed of materials that add up to the calorific value of the waste. This waste stream is usually called "refuse derived fuel" - in abbreviation RDF, and is made up of paper, cardboard, plastic, foils, textile and wood. The RDF is initially processed in the MBT plant from the municipal solid waste. Table 2 shows the results of the investigated materials included in the RDF.

\begin{tabular}{lc}
\hline Components & Share (\%) \\
\hline paper sum & 25 \\
\hline plastic sum & 6 \\
\hline wood, rubber and textile & 5 \\
\hline moist biological part & 25 \\
\hline micro waste (<8 mm) & 15 \\
\hline inorganic material (metal, mineral inert material) & 20 \\
\hline inseparable residue & 4 \\
\hline total & 100 \\
\hline
\end{tabular}

Table 1. Average structure of municipal solid waste in Germany [3] 


\begin{tabular}{lcccc}
\hline \multirow{2}{*}{ Components } & \multicolumn{3}{c}{ MATERIAL COMBUSTION PROPERTIES } \\
\cline { 2 - 5 } & Moisture & Ash & Combustibles & Heating value \\
\hline combustible fraction & & $(\%)$ & $(\mathrm{MJ} / \mathrm{kg})$ \\
\hline textile & 7,56 & 5,76 & 86,68 & 16,65 \\
\hline chart board & 6,85 & 11,88 & 81,27 & 17,49 \\
\hline soft paper & 23,99 & 12,43 & 63,58 & 10,1 \\
\hline plastic foil & 0,51 & 13,24 & 86,25 & 40,14 \\
\hline hard foil & 0,4 & 5,28 & 94,32 & 40,12 \\
\hline PET bottles & 0,42 & 0,15 & 99,43 & 21,51 \\
\hline wood & 12,52 & 2,31 & 85,17 & 16,32 \\
\hline styrofoam & 1,07 & 9,98 & 88,95 & 27,95 \\
\hline
\end{tabular}

Table 2. RDF components characteristics

The average fraction composition of RDF, based on our investigations, is quite versatile but can still be presented with data in the Table 3. The data in the table is based on the research of Slovenian RDF produced from municipal solid waste.

\begin{tabular}{lc}
\hline Fraction & Mass share [\%] \\
\hline textile & $12-16$ \\
\hline chard board & $10-15$ \\
\hline soft paper & $30-40$ \\
\hline plastic foil & $10-15$ \\
\hline hard plastic & $9-11$ \\
\hline PET bottles & $4-6$ \\
\hline wood & $2-4$ \\
\hline styrofoam & $0,5-1,5$ \\
\hline
\end{tabular}

Table 3. The average composition of Slovenian RDF

The MBT plant prepares the RDF according to the waste input stream quality, their technical capabilities and operation permits. Sometimes, to lower the operational costs, operators leave out certain sorting and processing systems thus produce coarser, lower-grade fuel with higher moisture and ash content. Still the RDF should be produced in accordance with the limits, set by the RDF utilizer. Such limits are for instance presented in Table 4 and were determined by the tests on pilot gasification unit by authors. If limits are not followed environmental and/or technical problems may arise during thermal treatment of RDF. 
The primary task of MBT is mechanical waste preparation and aerobic microbiologic waste treatment with the aim to biologically stabilize waste and dry it. Mechanical separation of combustible and incombustible part of waste follows. The combustible part usually has heating values between 15 and $20 \mathrm{MJ} / \mathrm{kg}$.

\begin{tabular}{ll}
\hline Parameter & Value \\
\hline moisture content: & between 20 and $45 \%$ \\
\hline metals content: & up to $2 \% \mathrm{~W}$ \\
\hline ash content: & between 15 and $30 \%$ \\
\hline chlorine $(\mathrm{Cl})$ content: & up to $1 \% \mathrm{~W}$ \\
\hline fluorine $(\mathrm{F})$ content: & up to $0,2 \% \mathrm{~W}$ \\
\hline nitrogen (N) content: & up to $1 \% \mathrm{~W}$ \\
\hline sulphur (S) content: & up to $0,3 \% \mathrm{~W}$ \\
\hline calorific value: & between 10 and $14 \mathrm{MJ} / \mathrm{kg}$ \\
\hline
\end{tabular}

Table 4. The certain parameters limits for RDF production and utilization

\section{Integrated waste management system}

The completely integrated waste management concept should be developed, build and in operation at regional level or really big cities for processing municipal solid waste. Such system is in economic terms effective if developed for over 200.000 people producing at least about $100.000 \mathrm{t} /$ year of municipal solid waste. If developed for special conditions like mountainous regions, less populated areas,... these figures can be half or third of above mentioned because logistics cost and its environmental influence would make it worse to generate high waste quantities.

The integrated system should be based on law enforced separated collection, composting, recycling, MBT of residual waste, $\mathrm{W}$-t-E of combustible fraction and disposal of inert fraction from MBT. Into the process of thermal treatment also sewage sludge from regional waste water treatment plants can be induced. Generally no special drying is needed for sewage sludge only mechanical dewatering process is utilized to squeeze the water out to get the sewage with about $25 \%$ of solids.

The operation of the integrated waste management system must realize multiple objectives related to environmental protection. The waste reuse is increased and its treatment is ensured. The amount of emissions into the ground and underground water and the amount of greenhouse gas emissions is radically reduced. The project protects surface and underground water and prevents water pollution.

The schematic presentation of the whole system is presented in Figure 1. 
The scheme represents material flow for the whole system. The technological processes are followed in the direction of arrows as depicted in the Figure 1.

Regional concept of integrated waste management should include:

- separate collection,

- sorting of separately collected fractions and recycling marketable part,

- composting of separately collected biodegradable fractions,

- MBT of rest of waste after separate collection

- thermal treatment of calorific fraction and waste residue from sorting plant together with sewage sludge from waste water treatment plant and

- land filling of biologically stable inert fraction and residue of thermal treatment.

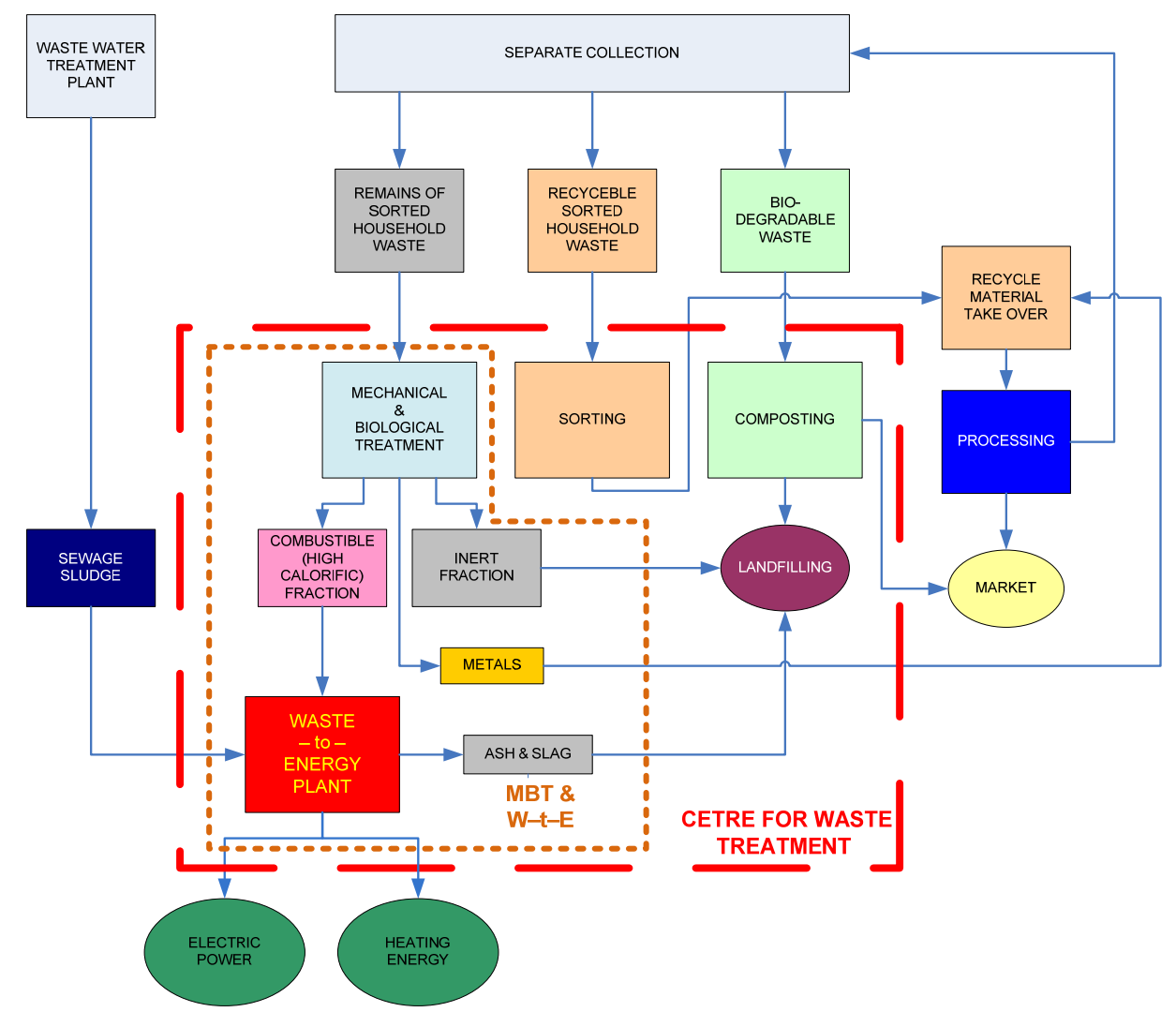

Figure 1. Schematic presentation of integrated waste management concept 
Local, regional and national integrated waste management concept must be composed of many closely related and connected technical and technological processes. With the aim to establish an environmentally and economically acceptable waste management it is essential for all the technological and logistical steps in the process of waste management to be interlinked and harmonised.

When building waste management strategy it is essential to regard cost and environmental impact. The priority list of waste management methods, based on European philosophy and directive [9] is:

- reduction of waste at the source,

- re-use and recycling of waste,

- energy recovery of waste and

- land filling of the waste residue.

To reduce the waste amount on the landfill, in accordance with the concept mentioned, waste must first be collected separately and then re-used or treated. In such manner the amount of the waste residue to be deposited on the landfill is minimised. The article shows many technical compliance arguments of the regional concept with the requirements, based on structural and chemical analysis of municipal waste and foreseen technology for waste treatment.

Separate collection ensures three collected waste stream of MSW and they are:

1. Biodegradable waste;

2. Recyclable sorted household waste (packaging waste);

3. Remains of the sorted household waste.

\subsection{Treatment of biodegradable waste}

The composting plant performs composting of separately collected biodegradable waste. The processes aerobic or anaerobic type of composting and run mostly in an enclosed hall, separately from the employees and the environment. The procedure is fully automated and controlled from the control room. The prepared composting mixture is handled only by appropriate technology. The composting process is designed to make the biodegradable waste decompose into compost in the shortest amount of time possible. For this purpose, the mass is constantly treated with air (aerobic process) which is an essential element for a quick and effective decomposition or just mixed in closed reactor (anaerobic process). Such conditions ensure the suitable quality of the end product.

The plant consists of three parts:

- the reception area,

- the composting area (reactor),

- the refining area (reactor). 
In case of anaerobic treatment biogas is produced. The biogas consists of $40 \%$ to $60 \%$ from methane and can be utilized in power and heat production. In developed countries it is generally used to power engines of turbines to produce highly subsidized electrical power. Technologies are also available to upgrade this biogas into bio-methane, having the same properties as natural gas what gives a possibility to inject this renewable source gas into national natural gas grid.

\subsection{Recycling sorted household waste}

The sorting plant allows separately collected raw materials, such as plastic, paper, cardboard and metals, to be additionally sorted, in line with the primary objective of the technological procedure - to produce the best quality fractions of plastic, e.g. polyethylene (PEHD, LDPE), polyethylene terephthalate (PET) and polystyrene (PS), and paper, cardboard and other secondary raw materials intended for further processing. Additional sorting is performed since the collection sites and centers collect various kinds of plastic, various kinds and qualities of waste paper and cardboard and various fractions of waste metal. In separate collection there are always impurities that have to be eliminated before handover of recyclable fractions.

\subsection{Treatment of the remains of the household waste}

The remains of the household waste is residual mixed municipal waste and is taken into MBT with the intend for biological stabilization of waste following further mechanical treatment. The waste is at the end of the process separated into combustible fraction (material to be utilized in W-t-E plants) and into inert fraction that is deposited at the landfill. The process of the mechanical and biological treatment of the remains of household waste is foreseen in the following treatment phases:

- waste intake at the reception area,

- biological treatment of the whole stream (biostabilisation and biodrying),

- grinding the waste,

- mechanical treatment and removal of combustible fraction of waste,

- at multiple intermediate phases there are metal separation units installed to take out ferrous and non-ferrous metals.

\section{Energy of waste and its conversion into useful energy}

Common W-t-E technologies utilize Rankin cycle for the production of electrical power. Generally the cycle operating media is water being within the cycle compressed and heated to superheated stem and on the other side after led through steam turbine condensates to liquid state.

Due to high corrosion problems within the boiler most plants operate with superheated steam of up to $400{ }^{\circ} \mathrm{C}$ and condensate the steam at temperatures well above $60^{\circ} \mathrm{C}$. These operating 
conditions limit the possibility for electrical power production to around $25 \%$ of input waste energy. This can be roughly calculated with simplified Eq. 1 having in mind that complete cycle total isentropic efficiency is calculated by multiplying all isentropic efficiencies of the cycle. This value is generally for W-t-E plants technology applied around 0.7.

$$
\text { Electrical power production eff. } \text { Rankine c. } \approx 1-\frac{\left(\frac{\text { Temperature of steam condensation }[\mathrm{K}]}{\text { Temperature of steam superheating }[\mathrm{K}]}\right)}{\text { Cycle total isentropic efficiency }}
$$

Legislation in European Union [9] has set strict limits for the beneficial utilization of energy produced by waste thermal treatment. The thermal treatment can only be regarded as "recovery operations" and not "disposal" if plants reach the energy efficiency of at least 0.65 set by Eq. 2.

$$
\text { Energy efficiency }=\frac{\text { Energy produced }- \text { Energy from fuels }- \text { Other energy imported }}{0.97 \times(\text { Energy of waste input }+ \text { Energy from fuels })}
$$

All energies in Eq. 2 are calculated in GJ/year. The term Energy produced in Eq. 2 means annual energy produced as heat or electrical power. It is calculated with the energy in the form of electrical power being multiplied by 2.6 and heat produced for commercial use multiplied by 1.1. The factor 0.97 is a factor accounting for energy losses due to bottom ash and radiation. To reach the set efficiency the most practical way is to maximize the electric power production.

New technologies are emerging on the market and by utilizing other thermodynamic cycles it is possible to achieve higher conversion efficiencies of the energy of waste into power. Those technologies are based on gasification or pyrolysis process and employ produced synthesis gas in gas engine or turbine.

To get a building permit for a waste thermal treatment in Europe today the new plant must in most cases fulfill this recovery standard.

Developed countries also largely support production of electrical power from renewable energy sources. Every country has developed its own scheme to support this production and they are called feed in tariffs. These tariffs add up to regular prices of electrical power, making this electrical power production very lucrative business.

Energy and environmental aspect make the energy utilization of waste justified and this process is obligatory in Europe to fulfill European waste directive demands. [9] Thermal waste processing must meet all legal requirements that define the process of waste incineration which is rather called waste recovery operations. [9] Heat generated can be used to produce electrical power, hot water for heating and cool media for cooling.

Main W-t-E process task is total thermal decomposition of hydro carbon materials in waste and the utilization of the energy, deposited in waste. Thermal conversion process products are inert materials. The quantity and toxicity of the remains and quantity of formed pollutants is primarily dependent of the process quality in the reaction chamber.[2] 
Main emphasis of this work is dedicated to optimize the conversion process to enhance the electrical power production of the waste-to-energy process.

\section{Technology background of high efficient Waste - to - Energy thermal conversion process}

The development of the high efficient electrical power production system could go into the direction of utilizing more advanced, high corrosion and stress resistant steels for boiler production or use or corrosion resistant plating on boiler tubes. The other possibility is to modify the whole $\mathrm{W}$-t-E process and this is presently investigated and tested by many researchers and companies. Some technologies have even been marketed with moderate real operating conditions success thus a lot of research and development (R\&D) is still needed to get a reliable and lasting operation of new high efficient technology.

Energy of waste conversion technologies were in the past solely based on combustion process similar to solid fuels combustion technologies. The only plant additions were demanding flue gas treatment devices to clean up the emitting pollutants.

Today, environmentally high efficient systems are based on multi stage thermal conversion process.

At first, two stage combustion systems have been designed for industrial, medical and hazardous waste incineration since in the past the legislation of developed countries had set higher environmental and technical standards for treating these wastes then treating the municipal solid waste. Those incinerators had small capacity and were mostly batch fired. The main intention for installing the second combustion chamber was to improve complete combustion of all organic components in gases leaving primary chamber. [2][13]

Multi stage incineration systems have made their first appearance some fifty years ago. All two (or multi) stage technologies share the common idea of two (or more) divided chambers (reactors). The two chamber combustion technology is in principle based on the air shortage in the primary chamber and excess air in the secondary chamber, what together assures good combustion conditions, low emissions and lower consumption of added fuel. [2][13]

The whole waste thermal treatment process is based on two groups of physical - chemical processes:

- warming, drying, semi-pyrolitic gasification of the waste in the primary chamber and

- mixing of the synthetic gases with air, ignition and complete combustion in the secondary chamber.

Two stage incineration system is in more technical detail presented in chapter Case study: presentation of small size waste - to - energy plant. 


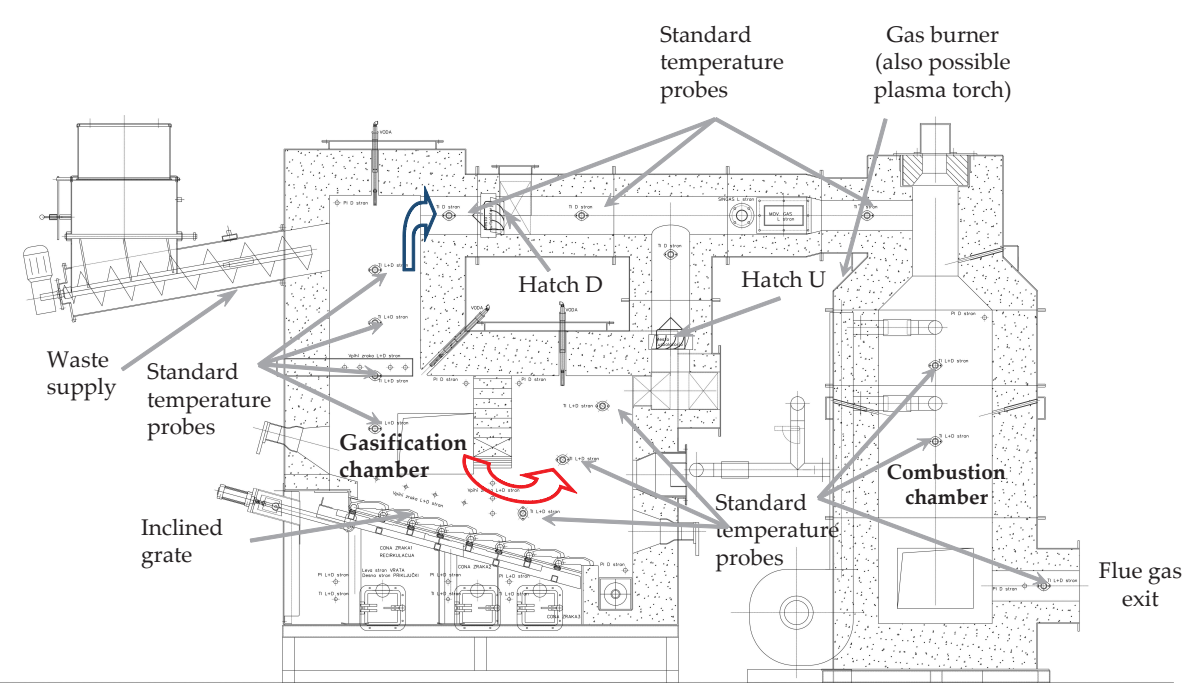

Figure 2. The schematic presentation of gasification and combustion chambers of pilot scale waste gasification unit

Gasification process emerged from combustion process as it is already present in every solid fuel combustor. Depending on the technology and waste (fuel) utilized can be updraft or downdraft system. These two terms define the movement of synthetic gas in co-flow (downdraft) or contra-flow (updraft) compared to waste movement. Other types of gasification technology are even more comparable to pure combustion technologies (like fluidized bed, rotary kiln,...).

The schematic presentation of gasification reactor or primary chamber and combustion or secondary chamber is presented on Figure 2.

The gasification chambers on Figure 2 and implemented technology can be regarded as modular waste processing on the grate. Waste processing is conducted in two stages - the designed process enables to upgrade the investigated system with utilization of high calorific synthetic gas in gas turbine or internal combustion gas engine instead of burning it in secondary chamber. The system enables both updraft and downdraft operating regimes, depending on input waste characteristic and reactor operating conditions. The photo of the pilot plant in presented on Figure 3.

In the primary chamber the gasification process is carefully managed with an exact air supply and temperature control. The system operates with air deficiency - compared to the theoretically required air for combustion, so pyrolytic gasification processes prevail. This is carefully controlled with under the grate air supply to ensure proper gasification process along the grate. The only possibility to overlook the gasification process along the grate in detail is to measure the temperature of the grate. As the upper side is covered with waste the only possibility is to measure the bottom side of the grate. 
This reactor design can in constant operation reach over $4 \mathrm{MJ} / \mathrm{Nm}^{3}$ with average composition of RDF produced in Europe. Thus the system allows downdraft (hatch D on Figure 2 closed) or updraft (hatch $U$ on Figure 2 closed) operation to be able to adjust the gasification to the properties of waste treated.

\begin{tabular}{lc}
\hline Gasifier type & Calorific value of the product gas [MJ/Nm $\left.{ }^{3}\right]$ \\
\hline downdraft & $4-6$ \\
\hline updraft & $4-6$ \\
\hline fluidized bed & $4-6$ \\
\hline fluidized bed - steam & $12-18$ \\
\hline circulating fluidized bed & $5-6.5$ \\
\hline cross flow & $4-6$ \\
\hline rotary kiln & $4-6$ \\
\hline
\end{tabular}

Table 5. Calorific value of synthetic gas produced with air and various gasifier types [17]

This utilization of synthetic gas in gas engine or turbine is only possible if high calorific synthetic gas is produced. The literature shows that the gases with the calorific value of between 4 and $6 \mathrm{MJ} / \mathrm{Nm}^{3}$ can be produced and the complete data is presented in Table 5. [17] The gas turbine can run on gases with calorific values as low as $2.5 \mathrm{MJ} / \mathrm{m}^{3}$.

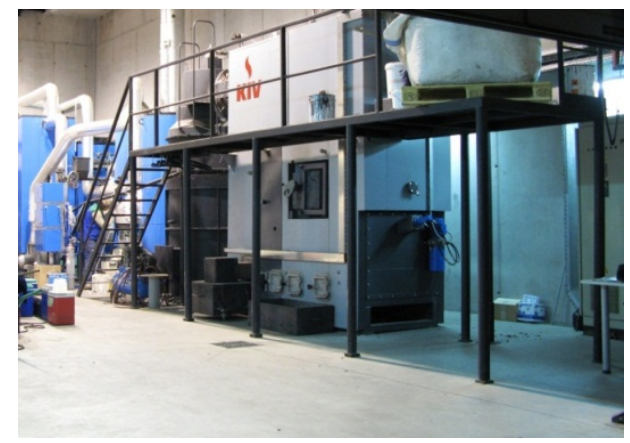

Figure 3. Pilot scale W-t-E gasification plant during experiments and investigations

The whole process of gasification was controlled with the quantity of waste input into the chamber, the velocity of waste movement along the grate and quantity and distribution of air. The search for optimal operating conditions was based on the known composition of waste and operating experience.

Generated synthetic gases are on the pilot scale system measured in the duct between primary and secondary chamber with Wobbe index analyzer [12]. The temperature in primary chamber needs to be kept more or less constant just over $600{ }^{\circ} \mathrm{C}$ and the air supply must be carefully controlled. 
The pilot scale equipment tests have shown that this technology can offer production of synthetic gases of over $4 \mathrm{MJ} / \mathrm{Nm}^{3}$. The generation of gas is highly dependent of the calorific value of the RDF. Test have shown that RDF with around $11 \mathrm{MJ} / \mathrm{kg}$ produces synthetic gases with around $2 \mathrm{MJ} / \mathrm{Nm}^{3}$ and only RDF with calorific value of $15 \mathrm{MJ} / \mathrm{kg}$ or over enables the production of synthetic gas of $4 \mathrm{MJ} / \mathrm{Nm}^{3}$ and over.

The syngas is composed of the $\mathrm{H}_{2}, \mathrm{CO}$ and $\mathrm{CH}_{4}$. These are the main components of the formed syngas, which have the energy value, and together with $\mathrm{CO}_{2}, \mathrm{~N}_{2}, \mathrm{O}_{2}$ and $\mathrm{H}_{2} \mathrm{O}$ represent more than $93 \%$ of the components in syngas. The rest are higher order hydro-carbons (ethane, propane, butane, benzene,...), some cyclical hydro-carbons (benzene, toluene,...) and other gases $\left(\mathrm{HCl}, \mathrm{HF}, \mathrm{SO}_{2}, \ldots\right)$. Higher-order hydro-carbons and cyclical hydro-carbons do have higher calorific value than $\mathrm{H}_{2}, \mathrm{CO}$ and $\mathrm{CH}_{4}$, but are found in the syngas in very low, negligible quantities.

Pyrolysis process is again is composed of thermal decomposition of organic matter which occurs in the absence of air. To reach decomposition conditions in reactor heat and sometimes steam need to be introduced to the reaction chamber.

The pyrolysis gas has at least double the calorific value as gasification synthetic gas both produced from the same waste (fuel). But the overall energy efficiency is not always in favor of pyrolysis as there is pyrolysis gas partially utilized for heat and steam generation.

To be able to compare all three thermal conversion processes in context of power production there are schematic presentations on Figure 4 to Figure 7.

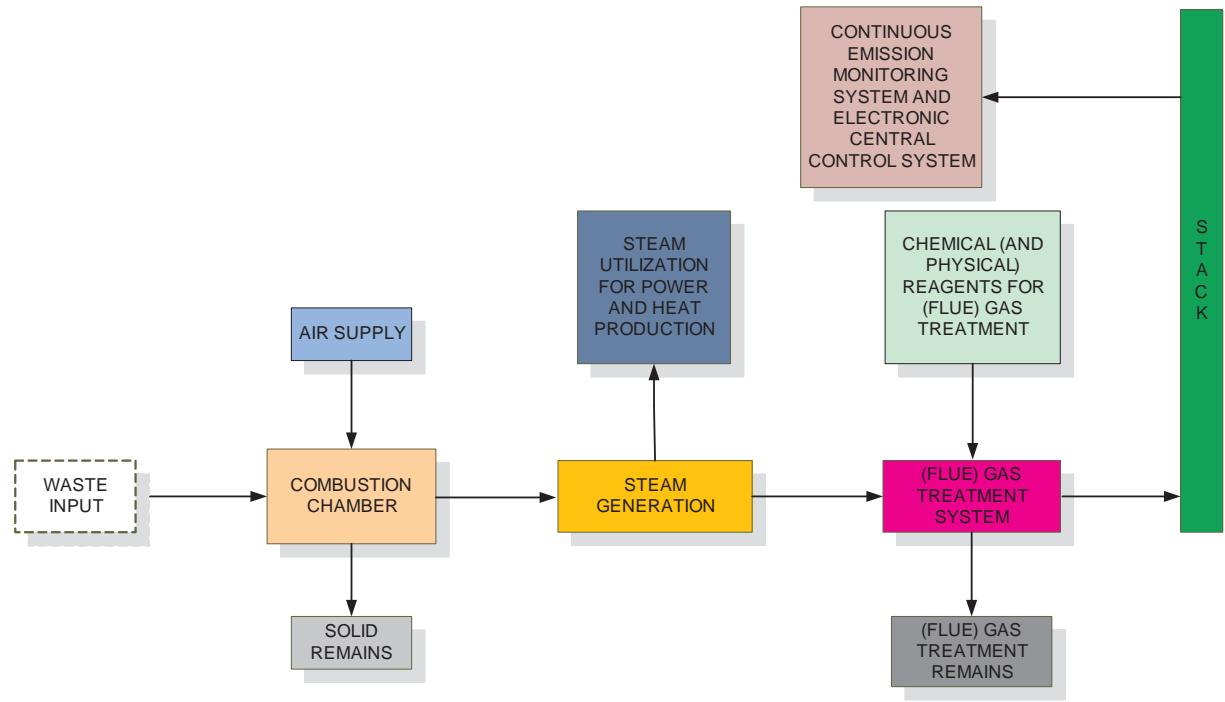

Figure 4. The schematic presentation of single stage combustion with steam generation and utilization 


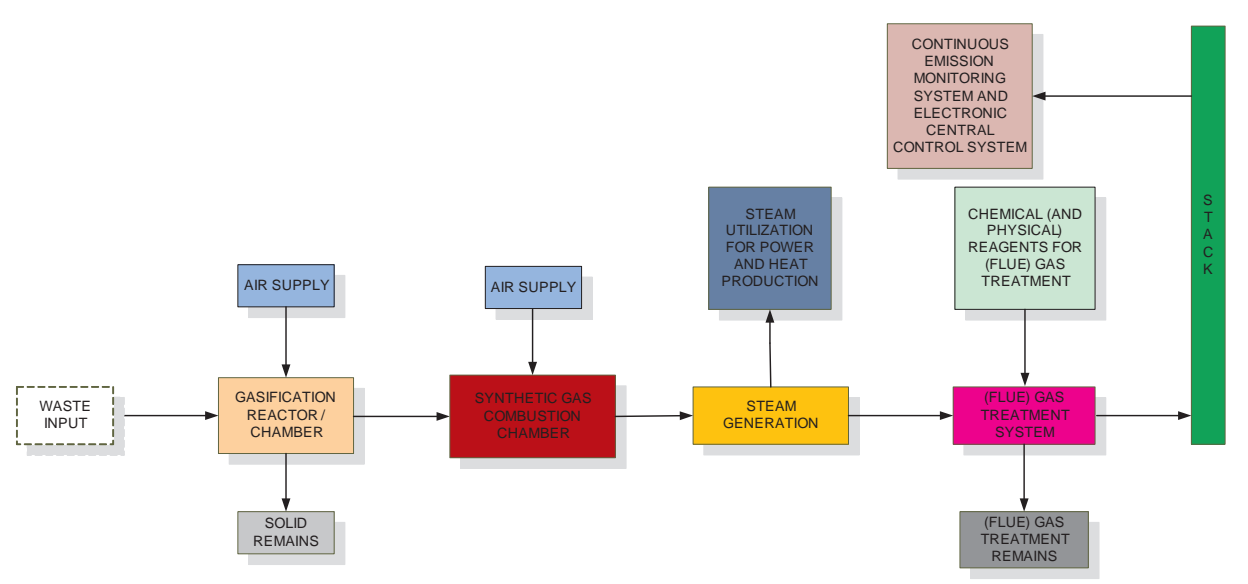

Figure 5. The schematic presentation of complete waste gasification system with immediate combustion of synthetic gas

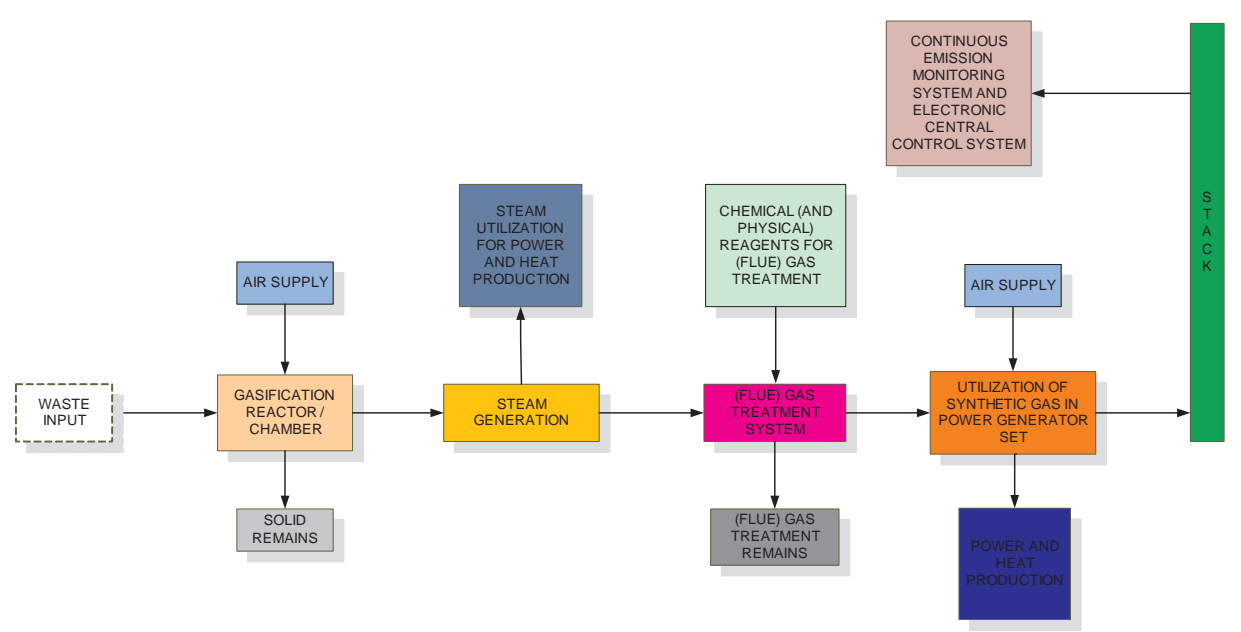

Figure 6. The schematic presentation of complete gasification system with high efficient electrical power production unit

Thermal conversion of waste with combustion can produce only hot water, hot thermal oil or steam (Figure 4). The power production can only be achieved with Rankine cycle with clear limitations of overall efficiency. Even when combustion occurs in multiple stages (chambers) it does not improve power production efficiency. It only improves environmental performance of conversion process.

On the other hand can gasification or pyrolysis process lead to higher power efficiencies since part of energy transformation and utilization takes place in gas engine or turbine with higher overall efficiency. This two processes have also quite some drawbacks especially is question- 
able the durability and reliability of this technologies with RDF operation. Generally these processes operate well with constant quality (properties) of waste (fuel) material without certain undesired materials that could cause problems along the conversion process.

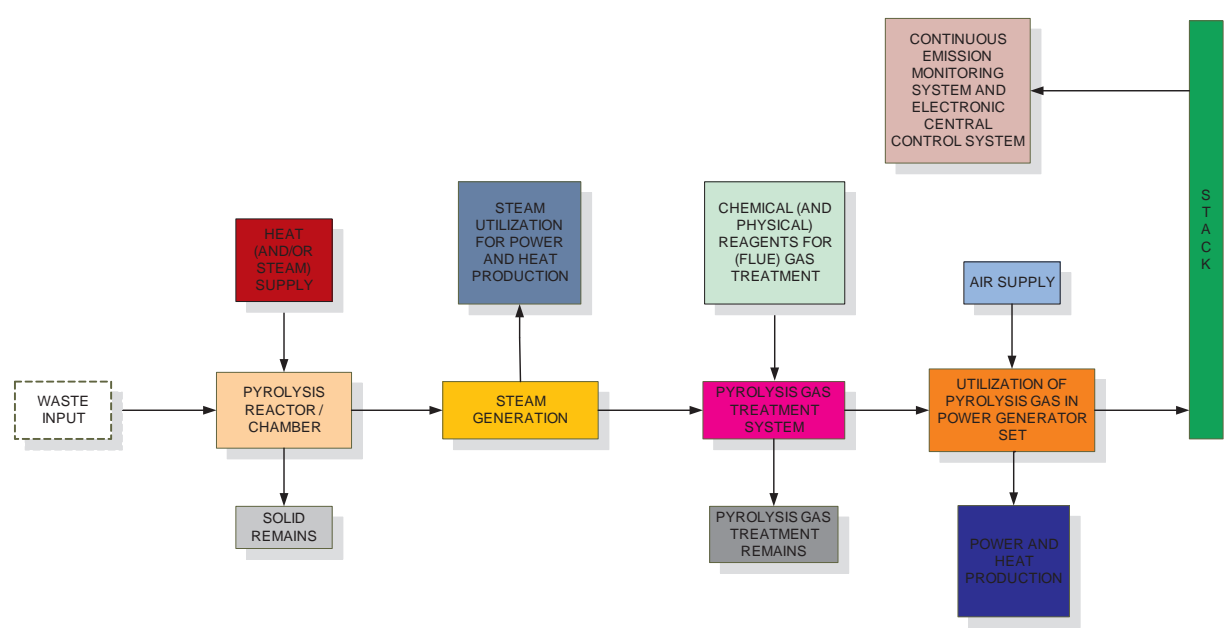

Figure 7. The schematic presentation of pyrolysis system with high efficient electrical power production unit

\section{Environmental impact of W-t-E plants}

The W-t-E plants have an environmental impact. In European legislation [8] is thermal treatment regarded as technology that needs to fulfill integrated pollution prevention control demands.

General image of the thermal treatment technologies is low and the spatial planning for these plants is extremely problematic and needs excellent cooperation among many professionals, from engineers to politicians. The last are very much under the influence of "not in my backyard" and "not in my election term" syndrome. To overcome this, everybody must realize that the complete environmental standards and environmental regulation requirements for such plants are met but still the most common environmental impacts of W-t-E plants are:

- emissions to air,

- ash and slag,

- flue gas treatment residue,

- emissions to water,

- emissions to ground,

- electromagnetic radiation, 
- heat emissions to air and water,

- noise,

- odor,

- increased traffic,

- utilization of space,...

In general the most considered and regarded as most harmful environmental impact is regarded emission to air. This is also the reason for the great opposition toward new plants.

The emissions of pollutants into the air are strictly controlled by national legislation or in case of European Union, also with Waste incineration directive [7] and are presented in Table 6.

A considerable advantage of advanced thermal conversion technology is the controlled conversion process and the low dust emissions in the gasses, which positively affects the reduction of the catalytic processes of harmful substances being produced during the flue gas cooling process and resulting in smaller quantities of flue gas treatment residue.

\begin{tabular}{|c|c|c|c|}
\hline $\begin{array}{l}\text { Parameter } \\
\text { (all parameters calculated on dry flue gas and } 11 \% \mathrm{O}_{2} \text { ) }\end{array}$ & $\begin{array}{c}100 \% \\
1 / 2 h\end{array}$ & $\begin{array}{c}97 \% \frac{1}{1 / 2} \\
h\end{array}$ & $24 \mathrm{~h}$ \\
\hline Total dust $\left[\mathrm{mg} / \mathrm{Nm}^{3}\right]$ & 20 & 10 & 10 \\
\hline $\mathrm{CO}\left[\mathrm{mg} / \mathrm{Nm}^{3}\right]$ & 20 & 10 & 10 \\
\hline $\mathrm{TOC}\left[\mathrm{mg} / \mathrm{Nm}^{3}\right]$ & 100 & - & 50 \\
\hline $\mathrm{SO}_{2}\left[\mathrm{mg} / \mathrm{Nm}^{3}\right]$ & 200 & 50 & 50 \\
\hline $\mathrm{NO}_{x}\left[\mathrm{mg} / \mathrm{Nm}^{3}\right]$ & 400 & 200 & 200 \\
\hline $\mathrm{HCl}\left[\mathrm{mg} / \mathrm{Nm}^{3}\right]$ & 60 & 10 & 10 \\
\hline $\mathrm{HF}\left[\mathrm{mg} / \mathrm{Nm}^{3}\right]$ & 4 & 2 & 1 \\
\hline $\mathrm{Cd}, \mathrm{Tl}$ - together $\left[\mathrm{mg} / \mathrm{Nm}^{3}\right]$ & 0,05 & - & 0,05 \\
\hline $\mathrm{Hg}\left[\mathrm{mg} / \mathrm{Nm}^{3}\right]$ & 0,05 & - & 0,05 \\
\hline $\mathrm{Ag}, \mathrm{Sb}, \mathrm{As}, \mathrm{Pb}, \mathrm{Cr}, \mathrm{Co}, \mathrm{Mn}, \mathrm{Ni}, \mathrm{V}, \mathrm{Sn}$ - together $\left[\mathrm{mg} / \mathrm{Nm}^{3}\right]$ & 0,5 & - & 0,5 \\
\hline $\mathrm{PCDD} / \mathrm{F}\left[\mathrm{TE} \mathrm{ng} / \mathrm{Nm}^{3}\right]$ & - & - & 0,1 \\
\hline
\end{tabular}

Table 6. Air emission limit values for waste incineration in European Union [7] 
The flue gas treatment includes the removal of dust particles, nitric oxides, acid gasses, potentially present organic substances and heavy metals. The design of the flue gas treatment system consists of multiple stages, designed for specific emission removal:

- reduction of nitric oxides:

- flue gas recirculation,

- selective non catalytic removal with ammonia water injection into combustion chamber at temperatures around $900{ }^{\circ} \mathrm{C}$,

- catalytic removal with ammonia water injection into flue gases at temperatures around $200^{\circ} \mathrm{C}$ to $300^{\circ} \mathrm{C}$;

- reduction of acid gases:

- wet, semi-wet, semi-dry or dry flue gas treatment with alkaline reagents (lime, sodium bicarbonate,...) and removal of neutralization products on fabric or ceramic filters;

- reduction of particles:

- with fabric or ceramic filters together with neutralization products or within wet washer systems;

- reduction of heavy metals and organic matter:

- coke adsorbent or activated carbon powder for the extraction of organic substances and heavy metals.

During combustion of RDF in W-t-E mass of input waste is reduced for about $90 \%$. The remains of combustion are mostly bottom ash. There are minor amounts of fly ash, boiler ash and flue gas treatment residue all classified as hazardous waste. The bottom ash composition and its amount from $\mathrm{W}$-t-E fed by RDF differ drastically from the bottom ash of conventional mass burning grate incinerators (MBGI) fed by untreated MSW[10] (not RDF). The bottom ash from RDF incineration offers different possibilities for its utilisation with similar composition to cement as shown in Table 7.

\begin{tabular}{cccc}
\hline \multirow{2}{*}{ Oxide } & \multicolumn{3}{c}{ Content (wt. \%) } \\
\cline { 2 - 4 } & Cement & RDF bottom ash & Untreated MSW bottom ash [10] \\
\hline $\mathrm{SiO}_{2}$ & 22.3 & 24 & $41.13-56.99$ \\
\hline $\mathrm{Al}_{2} \mathrm{O}_{3}$ & 5.83 & 14.8 & $9.2-11.35$ \\
\hline $\mathrm{Fe}_{2} \mathrm{O}_{3}$ & 2.17 & 2.7 & $3.97-8.61$ \\
\hline $\mathrm{CaO}$ & 60.81 & 39 & $13.22-19.77$ \\
\hline $\mathrm{MgO}$ & 2.82 & 1.7 & $3.46-3.85$ \\
\hline $\mathrm{Na}_{2} \mathrm{O}$ & 0.34 & 0.9 & $2.84-5.87$ \\
\hline $\mathrm{K}_{2} \mathrm{O}$ & 0.72 & 0.2 & $1.35-1.57$ \\
\hline
\end{tabular}

Table 7. Chemical composition of cement and bottom ash produced with incineration of RDF and untreated MSW 


\section{Case study: Presentation of small size Waste - to - Energy plant}

The W-t-E plant presented in this chapter is located in Celje, Slovenia.

The technology applied enables energy utilization (the combined heat and power production) of RDF produced from MSW with MBT and mechanically dried sewage sludge. Two stage combustion system has been applied as thermal treatment technology to ensure complete combustion and minimal influence on the environment.

The main goals for the investment were:

- energy utilization of waste to cover part of the heating energy needs in the city,

- meeting the strict requirements regarding the biodegradable carbon content in waste disposed of in the landfill after the year 2008 (base on European landfill directive [5])and

- sewage sludge disposal generated in the city waste water treatment plant.

The operation of the $\mathrm{W}$-t-E plant reduced the negative effects on the environment - in addition to the utilization of energy in waste. The waste and sludge incineration also substantially reduces the volume needed to landfill.

The W-t-E plant is located on the north-eastern rim of the city. In the urban planning documentation its location is declared as an industrial zone. The built surface of the W-t-E plant measures $2.000 \mathrm{~m}^{2}$ while the site of the plant including all the peripheral infrastructure and related technology covers $15.000 \mathrm{~m}^{2}$. The plant is designed to operate for 25 years and can be seen on Figure 8.

The W-t-E plant annually processes approximately 20,000 tons of RDF and 5,000 tons of sludge from the municipal waste water treatment plant with approximately $25 \%$ of solids.

The nominal thermal power of the plant is $15 \mathrm{MW}$ with ability for $2 \mathrm{MW}$ of power production. The power is supplied to the distribution network, while the heat energy is used in the district heating system for the city. The plant is designed to operate 24 hours a day, 7 day a week and 8000 hours per year. The schematic presentation can be seen on Figure 9.

The waste thermal treatment process is conducted in the following stages:

- transport and dosage of RDF and sludge to the combustion chamber in a ratio of 4:1,

- the multi step complete combustion of RDF and sludge mixure producing flue gases and ash,

- utilization (cooling) the flue gasses and production of super-heated stem for the combined heat and power production,

- flue gas treatment.

Prepared and mixed fuel is transported to the hoppers above the fuel screw feed dosing units situated above the furnace. These screw feeders provide a continuous and steady fuel feed into the primary chamber. As compared with discontinuous feeding (ram feed), with the continu- 


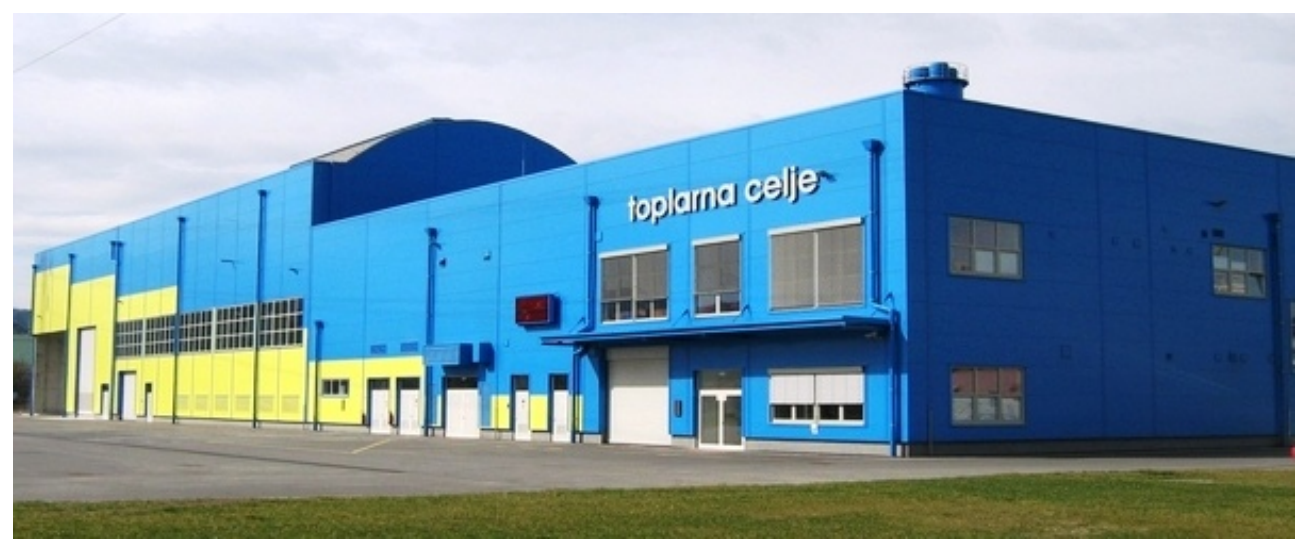

Figure 8. Celje W-t-E plant [3]

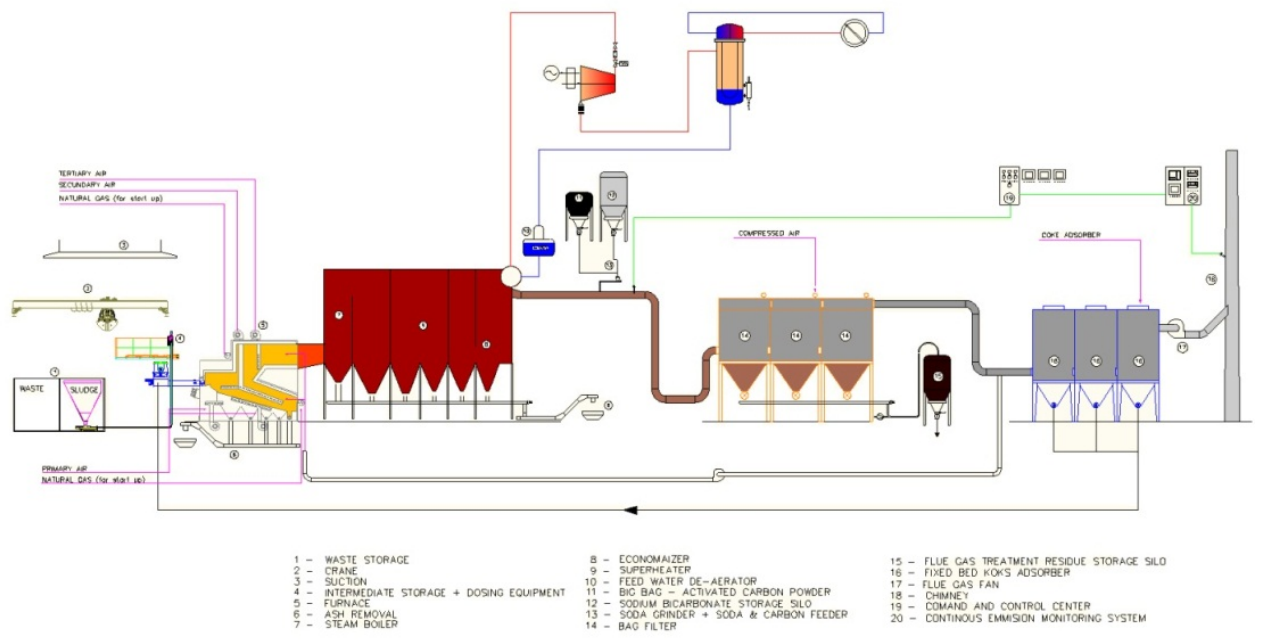

Figure 9. Schematic presentation of W-t-E plant

ous screw feeding system, a uniform combustion of fuel is assured and thereby extreme values of carbon monoxide and total organic carbon are minimized.

Feeding of fuel commences at startup of plant when the temperature in the furnace is at minimal value of $850^{\circ} \mathrm{C}$. To reach this high temperature the natural gas is used. If the temperature falls below this value or emission values exceeded, then the fuel feed is stopped. Fuel feed is continuously controlled and daily fuel consumption records are taken.

The combustion technology is the modular incineration on a grate. Waste combustion is conducted in two stages - in the primary and secondary chambers. In the primary chamber 
the combustion process is managed with an air deficiency - approximately $70 \%$ of the theoretically required air, so pyrolysis gasification processes prevail. Volatile and flue gases then travel to the secondary chamber for complete combustion. The temperature of the gases leaving the primary chamber is usually between 650 and $850^{\circ} \mathrm{C}$, as a large part of the generated heat is used in endothermic pyrolysis processes. The heterogeneous burning down of solid residue needs to be ensured towards the end of the revolving grate where the amount of air fed is sufficient for the complete oxidation of solid carbon.

In the secondary combustion chamber careful supply of secondary air in the mixing zone generates an optimum combustible mixture of air and volatile gases. In the following zone this mixture is ignited. Complete combustion is assured by correct mixing procedure and by supplying tertiary air. A special probe is fixed on the thermal reactor exit, which is used for measuring the oxygen contents in the flue gases, as well as accurate thermocouples. The quantity of the supplied secondary and tertiary air is regulated with reference to the measured value. The temperature of the thermal reactor is between $850{ }^{\circ} \mathrm{C}$ and up to $1200^{\circ} \mathrm{C}$, with a residency time of at least two seconds. These conditions ensure the complete combustion of organic substances together with the highly toxic polychlorinated biphenyls, polychlorinated dibenzodioxins, polychlorinated dibenzofurans and polycyclic aromatic hydrocarbons eventually generated in the primary chamber.

For startup preheating of secondary combustion chamber and to keep up the minimal burning temperature gas burners are installed. The burners are normally not required to operate, as normally the expected energy within the fuel is sufficient to maintain combustion.

The main components of the energy production system are the steam boiler, the steam turbine with the generator, air condenser and heat exchangers.

The feed water is vaporized in the water tube boiler and superheated to the temperature of $350{ }^{\circ} \mathrm{C}$ at 30 bars in the super heater. The superheated steam is then passed through the steam turbine, driving the power generator. The steam exiting the turbine is condensed in the heat exchangers for heating up water for district heating or in air condenser. Condensed water is then led over water preparation system and with the help of the boiler feed pump back to the boiler.

A computer controlled variable speed drive induced draft fan ensures correct negative pressure is maintained through the boiler and flue gas treatment system.

From the secondary chamber thermal reactor the hot gasses are ducted to the steam boiler. Just prior to entry into the boiler, ammonia water solution is sprayed in through atomizers. The solution in the high temperatures reacts with $\mathrm{NO}_{\mathrm{x}}$, thus reducing it back to nitrogen.

The flue gas treatment system is specially designed to the waste input data. The system removes solid particles (fly ash or dust), acid gases, heavy metals and persistent organic pollutants.

The acid gases are neutralized by alkaline additive injection into flue gases. The removal of heavy metals and persistent organic pollutants is usually done with activated carbon adsorbtion. As alkaline material the sodium bicarbonate is used. The material is grinded on site and 
prior to injection into flue gases the activated carbon powder is added. The neutralization residues and partially adsorbed heavy metals on activated carbon are removed from flue gases together with fly ash in textile bag filter.

As the end stage slue gas treatment system the fixed bed activated carbon system is applied. In ensures the final polishing of flue gases and ensures very low emissions of pollutants.

By using state-of-the-art technology all environmental, technical and economic requirements and stipulations are met. The plant is regarded within European legislation as IPPC plant and has this permit.[8]

Ash and slag from primary combustion chamber are not considered dangerous waste material, therefore are landfilled on local landfill site. The quantity depends on the inorganic content of the waste material input. Flue gas treatment residue stems contain increased quantities of metals and salts. It is therefore classified as dangerous waste. It's disposed at hazardous landfill site.

On Figure 7 is the presentation of operation confirmed yearly of W-t-E plant.

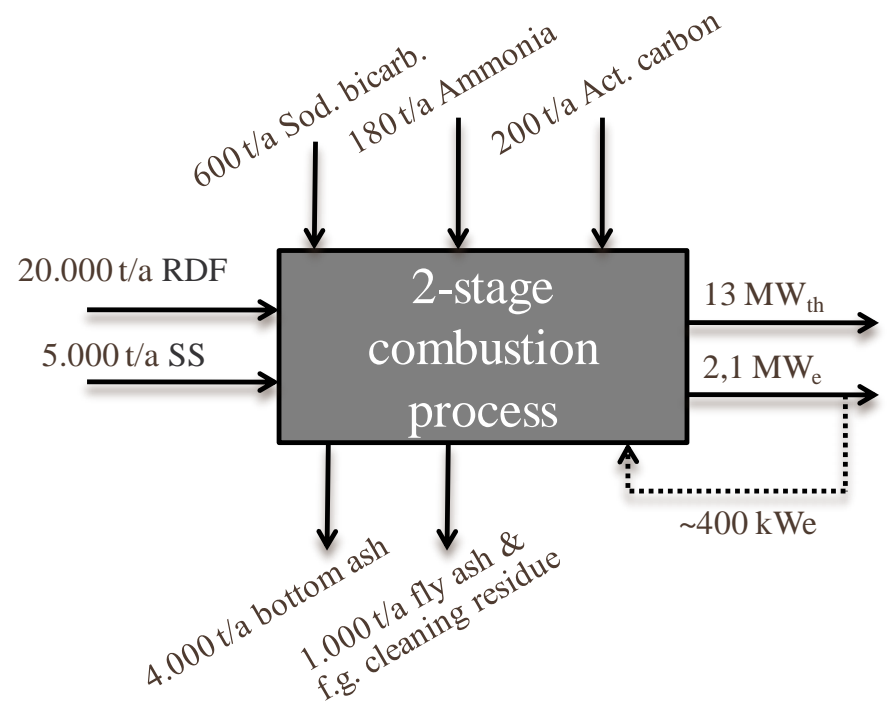

Figure 10. Schematic presentation of mass and energy conversion in W-t-E plant 


\section{Case study: W-t-E technology development with modern R\&D computational tool}

The combustion, gasification or pyrolysis chamber (reactor) needs to be modeled in such way to assure best possible process conditions for the production of complete thermal conversion of waste. For such modeling mostly advanced computer based engineering tools are used. [18][21]

The thermal conversion process by using municipal solid waste as a fuel in W-t-E plant calls for detailed understanding these phenomena. First, this process depends on many input parameters like proximate and ultimate analyses, season of the year, primary and secondary inlet air velocity and second, on the output parameters such as temperature or mass flow rate of conversion products. The variability and mutual dependence of these parameters can be difficult to manage in practice. Another problem is how these parameters can be tuned to achieve the optimal conversion conditions with minimal pollutants emission during the plant design phase. To meet these goals, $\mathrm{W}$-t-E plants are in the design phase investigated by using computational fluid dynamics (CFD) approach. The adequate variable input boundary conditions which are based on the real measurement are used and the whole computational work is updated with real plant geometry and the appropriate turbulence, combustion and heat transfer models. Different operating conditions are varied and conversion products are predicted and visualized.

CFD approach uses for description of conversion process in W-t-E a system of differential equations. Fluid mechanics of reacting flow is modeled with Reynolds Averaged NavierStokes equations (RANS), presented in the following form:

$$
\begin{gathered}
\frac{\partial \rho}{\partial t}+\frac{\partial}{\partial x_{j}}\left(\bar{\rho} \bar{v}_{j}\right)=0 \\
\frac{\partial}{\partial t}\left(\bar{\rho} \bar{v}_{j}\right)+\frac{\partial}{\partial x_{j}}\left(\bar{\rho} \bar{v}_{j} \bar{v}_{i}\right)=-\frac{\partial p}{\partial x_{i}}+\overline{f_{v i}}-\frac{\partial}{\partial x_{j}}\left(\bar{\tau}_{i j}+\overline{\rho v_{j}^{\prime} v_{i}^{\prime}}\right) \\
\frac{\partial}{\partial t}(\bar{\rho} \bar{h})+\frac{\partial}{\partial x_{j}}\left(\bar{\rho} \bar{v}_{j} \bar{h}\right)-\frac{\partial p}{\partial t}+\frac{\partial}{\partial x_{j}}\left(\bar{q}_{j}+\overline{\rho v_{j}^{\prime} h^{\prime}}\right)=\overline{I_{T}}
\end{gathered}
$$

Reynolds' stresses $\left(\overline{\rho v_{j}^{\prime} v_{i}^{r}}\right)$ are modelled by the introduction of turbulent viscosity $\eta_{t}$ :

$$
\overline{\rho v_{j}^{\prime} v_{i}^{\prime}}=\frac{2}{3} \delta_{i j}\left(\rho k+\eta_{t} \frac{\partial v_{k}}{\partial x_{k}}\right)-\eta_{t}\left(\frac{\partial v_{i}}{\partial x_{j}}+\frac{\partial v_{j}}{\partial x_{i}}\right)
$$


Turbulent viscosity can be determined using various turbulent models to close-down the system of Reynolds' equations. The two-equation $k-\varepsilon$ turbulent model is used for the purpose of the presented reacting flow modeling. Application of $k-\varepsilon$ turbulent model in the modeling of reacting flows has already been proven by many authors as a very successful one. Turbulent viscosity is computed using:

$$
\eta_{t}=\rho C_{\eta} \frac{k^{2}}{\varepsilon}
$$

where $k$ is turbulent kinetic energy $-k=0.5\left(\overline{v_{i}^{\prime} v_{i}^{\prime}}\right)$ and $\varepsilon$ its dissipation (irreversible transformation of kinetic energy into internal energy).

Local values of $k$ and $\varepsilon$ are computed using the following transport equations:

$$
\begin{aligned}
& \frac{\partial}{\partial t}(\rho k)+\frac{\partial}{\partial x_{j}}\left(\bar{v}_{j} k\right)-\frac{\partial}{\partial x_{j}}\left[\left(\eta+\frac{\eta_{t}}{\sigma_{k}}\right) \frac{\partial k}{\partial x_{j}}\right]=I_{k} \\
& \frac{\partial}{\partial t}(\rho \varepsilon)+\frac{\partial}{\partial x_{j}}\left(\bar{v}_{j} \varepsilon\right)-\frac{\partial}{\partial x_{j}}\left[\left(\eta+\frac{\eta_{t}}{\sigma_{\varepsilon}}\right) \frac{\partial \varepsilon}{\partial x_{j}}\right]=I_{\varepsilon}
\end{aligned}
$$

the source terms are modeled as:

$$
\begin{gathered}
I_{k}=\eta_{t}\left(\frac{\partial \bar{v}_{i}}{\partial x_{j}}+\frac{\partial \bar{v}_{j}}{\partial x_{i}}\right) \frac{\partial \bar{v}_{i}}{\partial x_{j}}-\rho \varepsilon \\
I_{\varepsilon}=C_{1} \frac{\varepsilon}{k}\left[\eta_{t}\left(\frac{\partial \bar{v}_{i}}{\partial x_{j}}+\frac{\partial \bar{v}_{j}}{\partial x_{i}}\right) \frac{\partial \bar{v}_{i}}{\partial x_{j}}\right]-C_{2} \rho \frac{\varepsilon^{2}}{k}
\end{gathered}
$$

Reynolds' enthalpy flux $\overline{\rho v^{\prime}{ }_{j}}{ }^{\prime}$ in Eq. 5 is also defined with turbulent viscosity:

$$
\overline{\rho v_{j}^{\prime} h^{\prime}}=-\frac{\eta_{t}}{\operatorname{Pr}_{t}} c_{p} \frac{\partial T}{\partial x_{j}}
$$

where $\operatorname{Pr}_{t}$ is the turbulent Prandtl number. $C_{\eta}, C_{1}, C_{2}, \sigma_{k}$ and $\sigma_{\varepsilon}$ are constants, and their values used in the presented work are: $C_{\eta}=0,09 ; C_{1}=1,44 ; C_{2}=1,92 ; \sigma_{k}=1$ and $\sigma_{\varepsilon}=1,3$. 
Advection - diffusive equation of mass species $\left(\xi_{k}\right)$ of the component $k$ has due to Reynolds' averaging, an additional term called turbulent mass species flux:

$$
\overline{\rho \xi_{k}^{\prime} v_{j}^{\prime}}=\frac{\eta_{t}}{\mathrm{Sc}_{t}} \frac{\partial \xi_{k}}{\partial x_{j}}
$$

and can be modeled with turbulent viscosity using the $k-\varepsilon$ model. The complete advection diffusive mass species equation is:

$$
\frac{\partial}{\partial t}\left(\overline{\rho \xi_{k}}\right)+\frac{\partial}{\partial x_{j}}\left(\overline{\rho v_{j} \xi_{k}}\right)-\frac{\partial}{\partial x_{j}}\left[\left(\rho D_{k}+\frac{\eta_{t}}{S c_{t}}\right) \frac{\partial \xi_{k}}{\partial x_{j}}\right]=\overline{I_{\xi_{k}}}
$$

where $\mathrm{Sc}_{t}$ is the turbulent $\mathrm{Schmidt}$ number and $D_{k}$ molecular diffusion coefficient of component $k$. With the new term:

$$
\Gamma_{k, \text { eff }}=\rho D_{k}+\frac{\eta_{t}}{\mathrm{Sc}_{t}}=\Gamma_{k}+\frac{\eta_{t}}{\mathrm{Sc}_{t}}
$$

the Eq. 14 can be rewritten as:

$$
\frac{\partial}{\partial t}\left(\overline{\rho \xi_{k}}\right)+\frac{\partial}{\partial x_{j}}\left(\overline{\rho v_{j} \xi_{k}}\right)-\frac{\partial}{\partial x_{j}}\left(\Gamma_{k, e f f} \frac{\partial \xi_{k}}{\partial x_{j}}\right)=\overline{I_{\xi_{k}}}
$$

Source terms of energy and mass species transport equations are computed by the following two equations where $\omega_{k}$ is computed by the turbulent combustion model:

$$
\begin{gathered}
\overline{I_{T}}=-\sum_{k=1}^{N} \Delta H_{f, k}^{o} \bar{\omega}_{k} \\
\overline{I_{\xi_{k}}}=M_{k} \bar{\omega}_{k}
\end{gathered}
$$

where $\Delta H_{f, k}^{\circ}$ is the standard heat formation and $M_{k}$ the molecular mass of the component $k$. In Eq. 17 and Eq. 18 the $\omega_{k}$ stands for the formation/consumption rate of component $k$ and is defined by the following expression:

$$
\bar{\omega}_{k}=\frac{d\left[X_{k}\right]}{d t}=\left(v_{k}^{\prime \prime}-v_{k}^{\prime}\right) \bar{R}_{k}
$$


which is written in following form of general chemical reaction:

$$
\sum_{k=1}^{N} v_{k}^{\prime} X_{k} \stackrel{k_{f}}{\stackrel{k_{b}}{\rightleftarrows}} \sum_{k=1}^{N} v_{k}^{\prime \prime} X_{k}
$$

Where $v{ }_{k}^{\prime}$ and $v{ }^{\prime \prime}{ }_{k}$ designate the stoichiometric coefficients of component $k$ for reactants and products, respectively. Chemical reaction rate $R_{k}$ in Eq. 19 is calculated by appropriate combustion models. It has to be pointed out that nowadays many turbulent combustion models are in practical use. Their application depends on the type of combustion (diffusion, kinetic, mixed), fuel type (solid, liquid, gaseous) and combustion device (furnace, boiler, engine). Most of models include various empirical constants which need to be individually determined case by case. In this case, on the base of best practice recommendations and its references [1] for this kind of combustion the Eddy Dissipation Combustion Model should be applied.

With CFD approach the combustion processes can be predicted and the operating conditions with combustion chamber design can be optimized in existing $\mathrm{W}-\mathrm{t}-\mathrm{E}$ or in the design project phase of the new one.
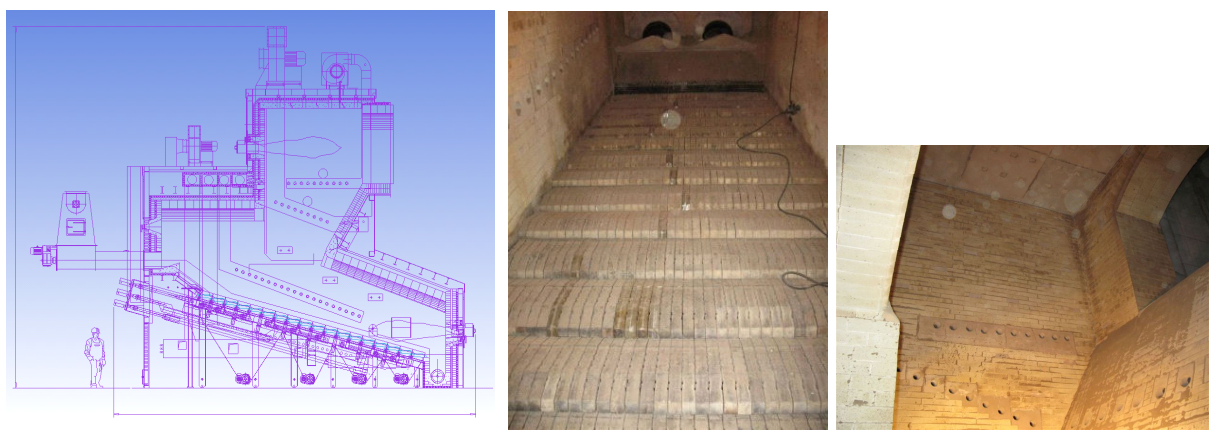

Figure 11. The $2 \mathrm{D}$ engineering plan and photos within built combustion chamber

Figure 11 shows $2 \mathrm{D}$ engineering plan view of $\mathrm{W}$-t-E plant. On this base the $\mathrm{W}$-t-E was built and operates with RDF. The photos of primary combustion chamber on Figure 11 were taken after plant was built.

Figure 11 shows grate details in the primary combustion chamber with waste input and the secondary combustion chamber with secondary and tertiary air inlet. Moreover, the exit of the secondary combustion chamber can be also seen.

The 3D geometry plan on the base of engineering plans in real measure was drown (Figure 12). Each dimension was marked on the plan with corresponding input dimensions which can be varied. In this way each dimension is easy and quickly modified and the entire construction can be modified and redrawn and further steps like mesh creation or design optimization is 
possible in real time. On this base, the mesh of 160,871 nodes and 810,978 elements (Figure 12) was created. It is very important that the mesh creation is designed optimally which means that the mesh is more dense in significant area like air input or when the combustion processes are very intensive such as in the primary and secondary combustion chamber. Due to these facts the optimal control volume size is needed and the remeshing iteration process is established to achieve the optimum mesh creation. That means that smaller control volume is applied where the combustion process is more intensive or at the reactants inlet of the W-t-E what is clearly seen in Figure 12.
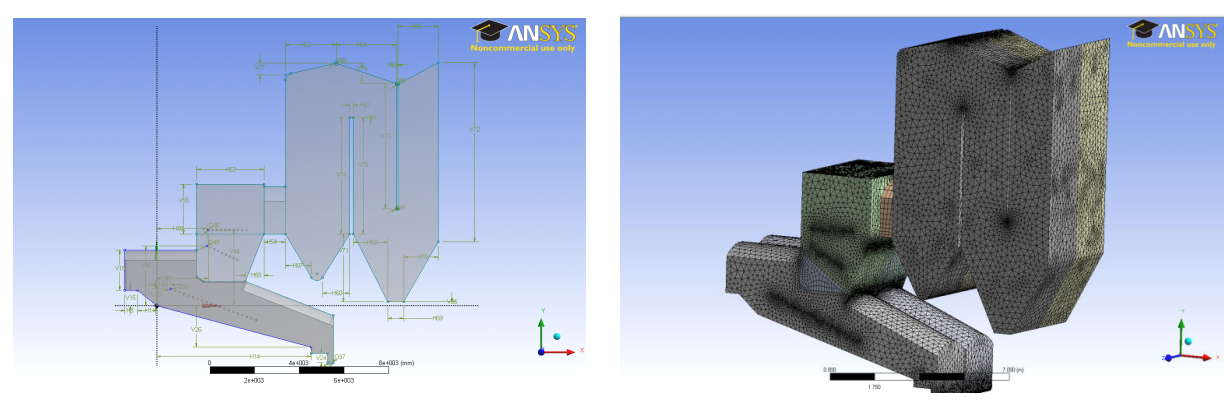

Figure 12. geometry plan of W-t-E with dimensions and geometry meshing

In addition the boundary conditions with entire combustion, radiation, particle tracking and other models with input and output parameters are set up and the solver is started to reach the convergence criteria like maximum number of iterations or residual target. These input parameters are operating conditions like intake velocities, temperatures, reactants mass flow rates, dimension values and the output parameters like temperatures, combustion products mass flow rate and other flue gas parameters. The boundary condition components of gaseous component are changeable and dependent on the distance of coordinate $\mathrm{x}$. In this work the boundary conditions are set as a polynomial function of variable $\mathrm{x}$ :

$$
\mathrm{f}_{k}(x)=\mathrm{a}_{k} x^{3}+\mathrm{b}_{k} x^{2}+\mathrm{c}_{k} x+\mathrm{d}_{k} ; \mathrm{k}=1 \ldots n ; \mathrm{a}, \mathrm{b}, \mathrm{c}, \mathrm{d}=\text { constants }
$$

corresponding to the statistics of the local measurements of specific gaseous components along the grate [11][14][20][21][19].

Figure 13 shows the marked area for primary, secondary and tertiary air inlet, fuel inlet and flue gases outlet. In addition, special cross section on secondary combustion chamber on inlet (SecIn) and outlet (SecOut) were created to identify and to monitor the combustion products and other parameters in this significant area. In this way, the location of single parameter can be distinguished. The $\mathrm{W}$-t-E operation optimization process was made by using design exploration which is a powerful tool for designing and understanding the analysis response of parts and assemblies. 


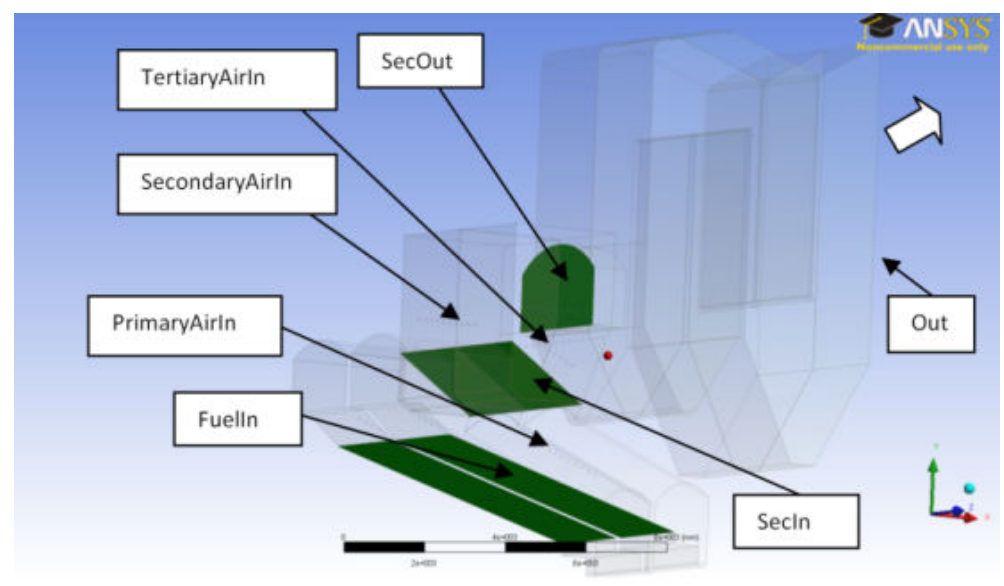

Figure 13. Area definition in W-t-E

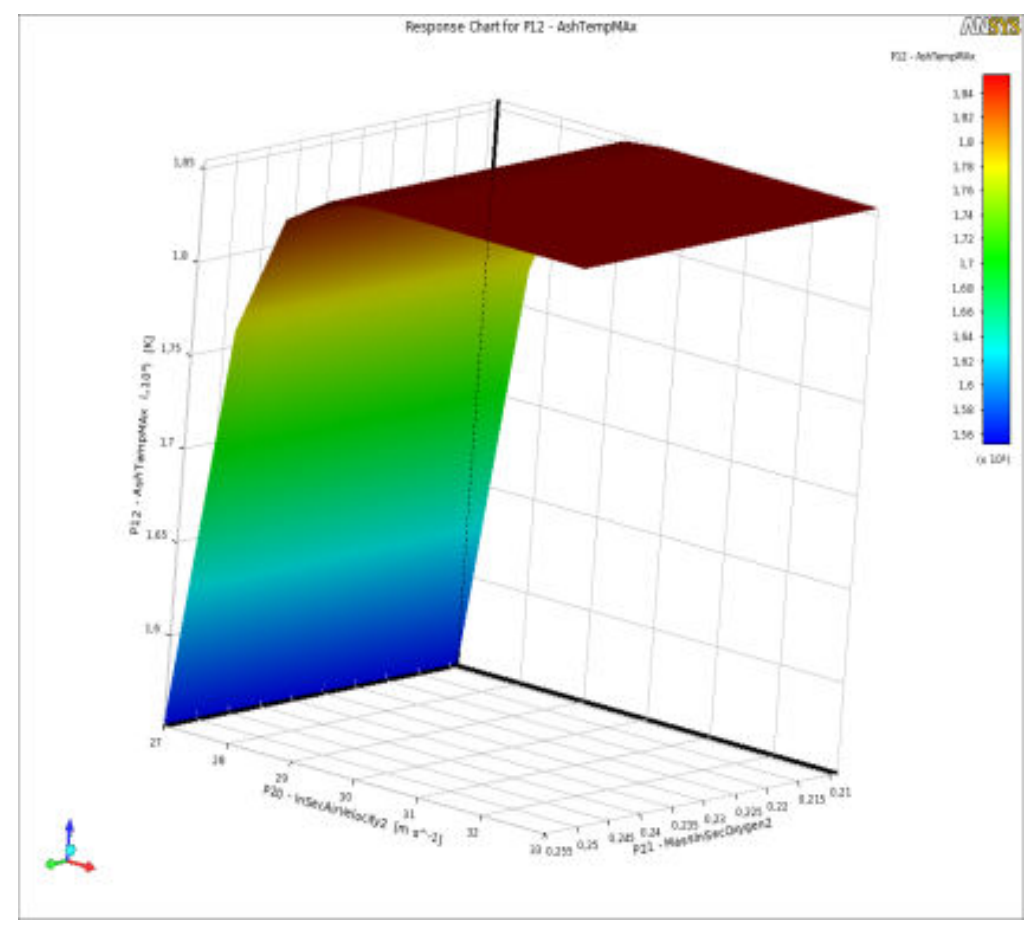

Figure 14. Simulation results for maximal ash temperature versus secondary air velocity and oxygen mass fraction in secondary air inlet 
Figure 14 shows analyses that help us to determinate the interaction among maximal ash temperature versus secondary air velocity and oxygen mass flow rate at secondary air inlet. The maximal ash temperature from secondary air velocity from $27 \mathrm{~m} / \mathrm{s}$ to $29 \mathrm{~m} / \mathrm{s}$ increases rapidly and picked the maximum ash temperature at $1,850 \mathrm{~K}$. On the other hand, there is no significant dependence of oxygen mass flow rate in region from 0.255 to 0.21 . In this way we can predict and avoid the possible damages cause by fly ash flagging on boiler tubes.

Figure 15 show results of temperature field comparison by different operating condition with different oxygen mass flow rates in case of enriched oxygen combustion. The temperature in secondary combustion chamber increases when oxygen enriched air is used [4] and this phenomena is clearly seen by temperature comparison on this picture. On the other hand, we have to be sure that the maximum ash temperature was not exceeded the ash melting point and we have to avoid fly ash deposit on heat exchangers walls which can cause a great damage.

Figure 16 shows 3D ash temperature particle tracking through the $\mathrm{W}$-t-E. The ash temperature changing through the $\mathrm{W}$-t-E and it was picked in the secondary combustion chamber where the oxygen enhanced combustion is used. In addition, the ash temperature has fallen due to the wall cooling. It was found out when the flaying ash clashes into the walls the probability of ash deposit at these sections is high.

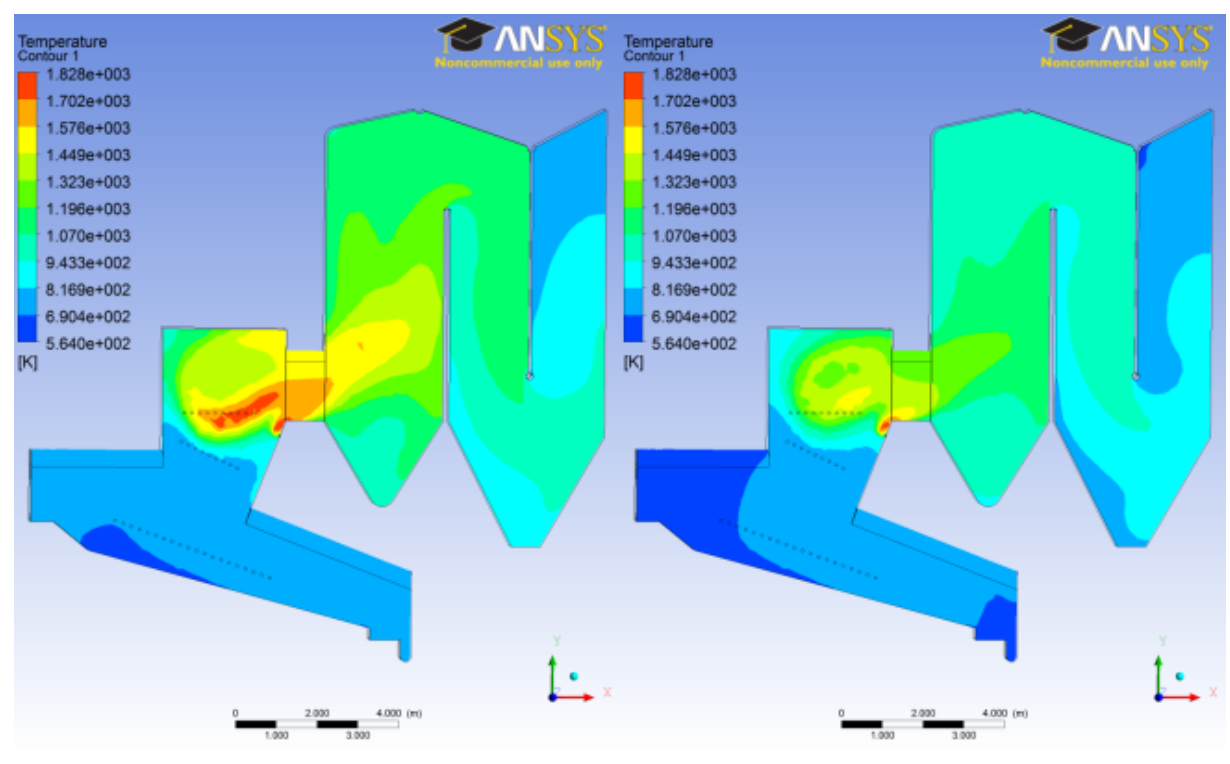

Figure 15. Temperature field by different oxygen mass flow rate at secondary enriched air inlet 

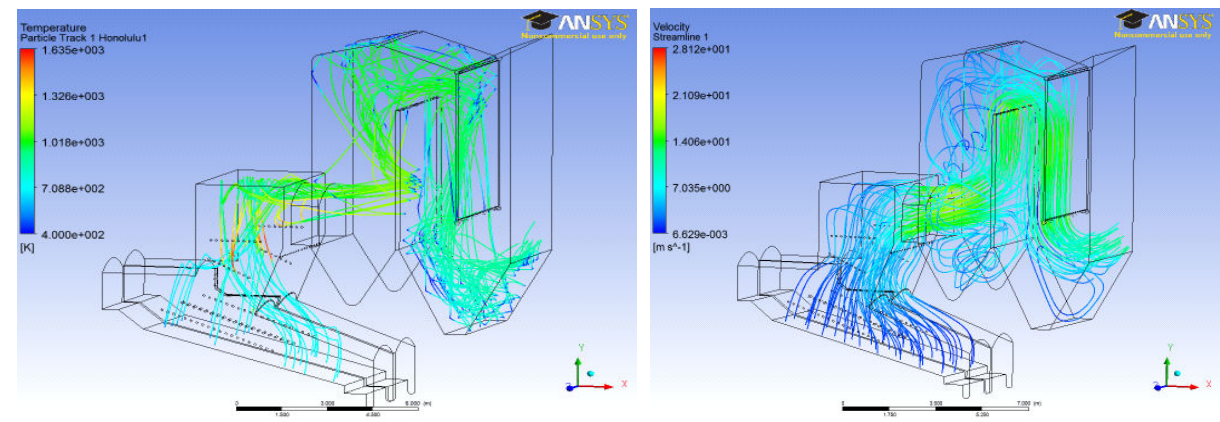

Figure 16. Ash temperature particle tracking and streamlines with velocity review

Streamlines with velocity review is shown in Figure 16. The majority of the stream takes the short way through $\mathrm{W}$-t-E and the velocity becomes higher at the exit of the secondary chamber. This must be taken into consideration when the residence time is calculated.

As shortly presented in this chapter the CFD with additional optimization features is the most convenient tool to predict the optimal conditions which have to be achieved to achieve the thermal and environmental efficiency and never to endanger the safety of the W-t-E operation. With this tool the problems because can be avoided and the whole situation can be predicted with appropriate inlet boundary conditions.

\section{Conclusion}

Waste presents a source of energy. The energy utilization is possible with the appropriate integrated waste management system and utilization of appropriate technologies within the legally permissible environmental impact. Such system can create power and heat or cold, which is distributed to the citizens or industry.

Future waste management is going to depend on $\mathrm{W}$-t-E technologies for the high calorific part of the waste stream, not suitable for recycling. The energy in waste will be utilized as the energy prices are not only high but are in constant rise. But the decision making process for the technology selection should not stand only on presented energy efficiency of the technology, thus only full scale long term tested technologies with proven environmental impact should be applied. 
Utilization of waste in $\mathrm{W}$-t-E plants means reducing greenhouse gas emissions, more rational management of energy and limited space for waste disposal.

Operational data of most $\mathrm{W}$-t-E plants show the following positive effects:

- the quantity of waste deposited at the landfill site is reduced by 80 to $85 \%$,

- the heat obtained from the incineration is used in the combined heat and power production;

- reduction (suppression) of greenhouse gas emissions from landfill site;

- reduction of national energy import dependence.

The produced heat of such systems should be used for the needs of the city district heating or industry. The power is partially used for the facility's own consumption and the surplus is placed in the power distribution network.

The correct operation approach and inclusion into city utility services makes the W-t-E plant more acceptable to the society and with such integral management generated MSW no longer present a problem but rather an energy and material source opportunity.

The heat of 1 ton of RDF approximately corresponds to $500 \mathrm{Sm}^{3}$ of natural gas thus a lot of money and fossil fuel can be saved by proper utilization of this alternative fuel source.

The regional integrated waste management strategy can be utilized in cost and environmental benefit for the citizens of populated region from around 200.000 inhabitants. The concept and technologies utilized in this work presented concept are completely in accordance to European legislation and strategic waste management documents. Each technology discussed is also a "Best available technology" for the segment considered.

Waste gasification and pyrolysis processes results on experimental devices show clear potential for high efficient electrical power production compared to standard waste incineration (combustion). The process solutions proposed should be real environment and full scale tested thus present environmentally and financially safe investment. The achieved calorific values of synthetic gases are in the acceptable range for utilization in gas engine or turbine what gives a good utilization potential. Such solutions will raise power production from RDF well over $30 \%$.

The applicability of advanced engineering computer simulation tools should become standard for every R\&D in W-t-E technology design. CFD can provide analyses results, comparable to tests on full scale equipment. The CFD approach and the numerical optimization can be used to identify the appropriate conditions to achieve complete conversion conditions, minimize the environmental impact, operating troubleshooting and keep operating costs on reasonable level.

CFD approach can offer huge benefits and provide numerical optimization of the operating conditions without expensive and long duration measurements and different operating conditions. In this way, this optimization can be used not only for operating parameters prediction of built $\mathrm{W}$-t-E but also in the project design phase which would reduce the research and development costs. 


\section{Abbreviations}

\begin{tabular}{ll}
\hline 2D - two dimensional & MSW - municipal solid waste \\
\hline 3D - three dimensional & PEHD - high-density polyethylene \\
\hline CFD - computational fluid dynamics & PET - polyethylene terephthalate \\
\hline Eq. - equation & PS - polystyrene \\
\hline EU - European Union & R\&D - research \& development \\
\hline IPPC - integrated pollution prevention control & RANS - Reynolds Averaged Navier-Stokes \\
\hline LDPE - low-density polyethylene & RDF - refuse derived fuel \\
\hline MBGI - mass burning grate incinerator & W-t-E - waste - to - energy \\
\hline MBT - mechanical and biological treatment & \\
\hline
\end{tabular}

\section{Symbols}

\begin{tabular}{|c|c|}
\hline a- constant & $\overline{\bar{l}_{\xi_{k}}}$ - chemical source term \\
\hline b constant & $\overline{I_{T}}$-combustion source/sink term \\
\hline c-constant & $\bar{q}_{j}$ - heat flux \\
\hline$C_{\eta}$ - constant & $\bar{\rho}$ - mean value of density \\
\hline$C_{1}$ - constant & $\bar{h}$ - mean value of enthalpy \\
\hline$C_{2}$ - constant & $\bar{u}_{j}$ - mean value of fluid velocity \\
\hline$\sigma_{k}$ - constant & $\rho \bar{v}_{j}^{\top} \varphi^{\prime}-$ Reynolds' fluxes \\
\hline$\sigma_{\varepsilon}-$ constant & $\rho v^{\top}{ }_{j}{ }^{\prime}{ }_{i}-$ Reynolds' stresses \\
\hline$c_{p}$ - specific heat & $\bar{f}_{u i}-$ sum of all volume forces \\
\hline$d$ - constant & $\dot{i}_{i j}-$ viscous stress tensor \\
\hline Dk - molecular diffusion coefficient of component k & $\varepsilon$ - turbulent kinetic energy dissipation \\
\hline$f$-function & $\Delta H_{f, k}^{\circ}$ standard heat of formation of component $k$ \\
\hline$I_{\varepsilon}$ - turbulent kinetic energy dissipation source/sink term & $\omega_{k}$ - formation/consumption rate of component $k$ \\
\hline$I_{k}$ - turbulent kinetic energy source/sink term & $\begin{array}{l}v_{k}^{\prime \prime} \text {-stoichiometric coefficients of component } k \text { for } \\
\text { products }\end{array}$ \\
\hline k-component & $\begin{array}{l}v_{k}^{\prime} \text {-stoichiometric coefficients of component } k \text { for } \\
\text { reactants }\end{array}$ \\
\hline k-turbulent kinetic energy & $\eta_{t}-$ turbulent viscosity \\
\hline$M_{k}$ - molecular mass of the component $k$ & $R_{k}$-chemical reaction rate \\
\hline$p$-pressure & $\mathrm{SC}_{t}$ - turbulent Schmidt number \\
\hline $\mathrm{Pr}_{t}$ - turbulent Prandtl number & \\
\hline
\end{tabular}




\section{Author details}

Filip Kokalj" and Niko Samec

*Address all correspondence to: filip.kokalj@um.si

Laboratory for combustion and environmental engineering, Faculty of Mechanical Engineering, University of Maribor, Smetanova , Maribor, Slovenia

\section{References}

[1] ANSYSInc., Southpointe, 275 Technology drive, Canonsburg, PA 15317, United States, Software package Workbench 2 with CFX 12.0: Help Mode;

[2] Brunner Calvin RHandbook of Incineration Systems, McGraw- Hill, Inc., New York (1991).

[3] Celje W-t-E- Celje District Heating Plant. www.toplarna-ce.si;.

[4] Charles E Baukal, Oxygen enhanced combustion, CRC Press, (1998).

[5] Council Directive 1999/31/EC of 26 April 1999 on the landfill of wasteOfficial Journal L 182, 16/7/(1999). , 1-19.

[6] Daniel Hoornweg and Perinaz Bhada-TataWHAT A WASTE; A Global Review of Solid Waste Management, Urban Development \& Local Government Unit, World Bank, March (2012). (15)

[7] Directive 2000/76/EC of the European Parliament and of the Council of 4 December 2000 on the incineration of waste; Official Journal L 33200910111

[8] Directive 2008/1/EC of the European Parliament and of the Council of 15 January 2008 concerning integrated pollution prevention and controlOfficial Journal L 24, 29/1/(2008). , 8-29.

[9] Directive 2008/98/EC of the European Parliament and of the Council of 19 November 2008 on waste and repealing certain Directives; Official Journal L 31200030030

[10] Filipponi, P, Polettini, A, Pomi, R, \& Sirini, P. Physical and mechanical properties of cement-based products containing incineration bottom ash; Waste Management. (2003). , 2003(23), 145-156.

[11] Hens-Heinz FreyBernhard Peters, Hans Kunsinger, Jürgen Vehlow, Characterization of municipal solid waste combustion in a grate furnace, Waste Management, 23, (2003). , 689-701. 
[12] Hobre Instruments WDM 3300 Wobbe Index MeterHobre Instruments. http:// www.hobre.com/files/products/WIM3300_incl_SG_cell.pdf;

[13] Niessen Walter RCombustion and Incineration Processes: Applications in Environmental Engineering, Second Edition, Revised and Expanded, Marcel Dekker, Inc., New York (1995).

[14] Anderson, S. R, Kadirkamanathan, V, Chipperfield, A, Sharifi, V, \& Swithenbank, J. Multi-objective optimization of operating variables in a waste incineration plant, Computer \& chemical Engineering, 29, (2005). , 1121-1130.

[15] Sattler, K, \& Emberger, J. Behandlung fester Abfaelle, 4. ueberarb. Aufl., Vogel Verlag und Druck KG, Wuerzburg, (1995).

[16] Data, U. N. A world of information, web page accessed in December (2012). http:// data.un.org/Data.aspx?q=municipal+wastes\&d=ENV\&f=variableID\%3a1814

[17] Williams Paul TWaste Treatment and Disposal, Willey, 2nd edition, (2005).

[18] Won YangHyung-sik Nam, Cangmin Choi: Improvement of operating conditions in waste incineration using engineering tools, Waste Management, 27, (2007). , 604-613.

[19] Yang, Y. B, Goh, Y. B, Zakaria, R, Nasserzadeh, V, \& Swithenbank, J. Mathematical modelling of MSW incineration on a travelling bed, Waste management, 22, (2002). , 369-380.

[20] Yao Bin YangJim Swithenbank, Mathematical modelling of particle mixing effect on the combustion of municipal solid wastes in a packet-bed furnace, Waste Management, 28, (2008). , 1290-1300.

[21] Yao Bin YangVida N. Sharifi, Jim Swithenbank, Converting moving-grate incineration from combustion to gasification- Numerical simulation of the burning characteristics, Waste Management, 27, (2007). , 645-655. 
